University of Nebraska - Lincoln

DigitalCommons@University of Nebraska - Lincoln

Architectural Engineering -- Faculty Publications

Architectural Engineering and Construction,

Durham School of

3-2006

\title{
Measuring Sound Power in Ducted Heating, Ventilating, and Air- conditioning (HVAC) Systems for Use in Verifying Acoustical Prediction Methods
}

\author{
Steven R. Ryherd \\ University of Nebraska - Lincoln \\ Lily M. Wang \\ University of Nebraska - Lincoln, Iwang4@unl.edu
}

Follow this and additional works at: https://digitalcommons.unl.edu/archengfacpub

Part of the Architectural Engineering Commons

Ryherd, Steven R. and Wang, Lily M., "Measuring Sound Power in Ducted Heating, Ventilating, and Airconditioning (HVAC) Systems for Use in Verifying Acoustical Prediction Methods" (2006). Architectural Engineering -- Faculty Publications. 15.

https://digitalcommons.unl.edu/archengfacpub/15

This Article is brought to you for free and open access by the Architectural Engineering and Construction, Durham School of at DigitalCommons@University of Nebraska - Lincoln. It has been accepted for inclusion in Architectural Engineering -- Faculty Publications by an authorized administrator of DigitalCommons@University of Nebraska Lincoln. 


\title{
Measuring Sound Power in Ducted Heating, Ventilating, and Air-conditioning (HVAC) Systems for Use in Verifying Acoustical Prediction Methods
}

\author{
Steven R. Ryherd and Lily M. Wang \\ Architectural Engineering Program, University of Nebraska—Lincoln, PKI, $1110 \mathrm{~S}$. \\ 67th St., Omaha, NE 68182; PH (402) 554-2065; FAX (402) 554-2080; email: \\ sryherd@mail.unomaha.edu
}

\begin{abstract}
This paper discusses issues regarding in-situ methods of obtaining sound power at a point in a heating, ventilating and air-conditioning (HVAC) duct system. Such a method is being used as part of a larger investigation on acoustical prediction methods to allow for comparison of measured data to results from attenuation predictions of individual duct elements, such as elbows or dampers. Sound propagation in HVAC duct work is complex. Any measurements of sound energy in the duct must address the characteristics of sound propagation in ducts, end reflections, and air turbulence. Investigations are being conducted to understand the extents to which these acoustical issues affect measurement results. The study provides a better understanding of sound propagation in HVAC ducts for future investigation of acoustical prediction methods.
\end{abstract}

\section{Introduction}

The study outlined in this paper is part of a larger investigation of acoustical prediction software for heating, ventilating, and air-conditioning (HVAC) systems. The authors have previously investigated prediction software for HVAC systems along entire acoustical paths from the fan source to the receiver in a room (Ryherd \& Wang, 2005). Such verification of the prediction software required controlled environments with well-documented information about the actual sound source power, duct elements, and receiving room characteristics. In an attempt to verify the algorithms used against actual data measured in field installations, though, it is desired to limit other potential sources of error.

This paper presents the issues surrounding an in-situ method of investigating the acoustical influence of each element in the duct path separately. To verify each duct element's contribution, there must be dependable means of obtaining a sound power level at the inlet and outlet of the specified element. These sound power levels could then be compared to the expected attenuation of that element, as currently 
projected in HVAC noise prediction software. However, in-situ measurements of this kind are not common, especially in installed HVAC systems.

\section{Background}

Sound prediction software for noise in HVAC systems utilize a collection of algorithms that calculate the attenuation contributions of each element of a system. In general, the algorithm is an empirical black box that takes an incoming sound power level and characteristic information of the element to produce an output sound power level. For example, if a fan is used as the sound source at the beginning of a length of duct, the sound power levels at each octave band are put into the algorithm for the specific type of duct (e.g. rectangular, circular, etc.) along with the duct dimensions, duct length and amount of absorption. The algorithm calculates the amount of sound attenuation and projects the output sound power level. This process continues down the path of the HVAC system for each element of the path (silencers, elbows, branches, etc.) until the sound reaches the receiver room. At the receiving room, correction factors are applied to the estimated sound power level to calculate the equivalent sound pressure level perceived by a receiver in the space.

Although the example is simply stated, the process of predicting the noise in HVAC systems is complex with many potential sources of error. There is inherent error when algorithms based on empirical data made in controlled environments are used for in-situ applications; and unfortunately, users of software programs often are not able to access even what algorithm is being used to know if its application is appropriate. Additionally, the initial source data from a fan is not always reliable and may vary based on operating conditions and installation. Ultimately, any inaccuracies at one point in the analysis of the system can compound errors further down the system path. To improve acoustical predictions along HVAC ductwork, one should first be sure to understand sound propagation in ducts.

\section{Relationship of Sound Pressure and Sound Power}

In acoustics of building mechanical systems, sound energy is often represented as one of two quantities: sound pressure levels or sound power levels. Sound pressure level is the most common form of describing the human response to airborne sound, and measures the changes in pressure with respect to static pressure. This quantity is dependent upon the distance of the receiver to the source and the environment in which it is measured. However, another quantity, sound power level, is independent of distance to the source and the environmental characteristics of the space. Sound power describes the rate at which sound energy is produced by a source and is used to quantify the sound energy relating to mechanical equipment. Using an acoustical predictor that is independent of the environment allows for simple comparison of acoustical characteristics of mechanical equipment. 
Although sound power is a common descriptor of acoustical energy, there is no easy way to measure sound power directly. A collection of sound pressure measurements can be used to calculate sound power. Other information is necessary including the directivity of the source, the distance of the measurements, environmental characteristics, and the area that the measurements cover. The actual equation used for converting between sound pressure level and sound power level varies with the situation (Bies \& Hansen, 2003).

\section{Sound Propagation in Ducts}

There are three issues associated with the sound propagation in ducts that affect in-duct measurements-the characteristics of acoustical energy in ducts, end reflections, and turbulence. The first issue of acoustical characteristics depends on the dimensions of the duct and the frequencies being measured. At lower frequencies with large wavelengths, only plane waves propagate in a duct and a simple relationship can be shown between sound pressure and sound power. At high frequencies with shorter wavelengths, plane modes and higher order modes can exist. This means that sound is propagating not only parallel to the axis of the duct but also in various angles due to reflections off the wall of the duct. These modes cause variations in the sound pressure level at particular locations in a cross-sectional area of the duct. Modes in the duct will vary based on the dimensions of the duct and the frequency of the measurements. These modes can cause interference that results in a change in measured energy.

The second issue when taking in-duct measurements is end reflection factors due to duct termination. An opening at the discharge of a duct can create end reflections that send a sound wave back into the duct against the airflow because of an impedance mismatch. The reflections can cause interference and generate standing waves that further complicate the patterns of sound energy being transmitted through each element of the duct system. Such standing waves in the duct can cause inaccuracies with in-duct measurements of element contributions.

The third issue with in-duct measurements is turbulence caused by the movement of air in the duct. Turbulence can be caused by obstructions to the flow and other changes in pressure. The resulting turbulent eddies have flow that may not be parallel to the axis of the duct. The turbulent fluctuations in pressure can not be differentiated by a microphone measuring the pressure changes associated with acoustical energy. These pressure fluctuations affect random frequencies of measurements taken in such a condition (Liao, 1990).

\section{Measuring Sound Energy in Ducts}

All three sound propagation issues must be addressed when making in-duct measurements to obtain reliable acoustical data. In existing standards, the three issues are addressed by obtaining the data in a controlled laboratory environment. These 
existing standards can serve as a guideline to create a method of in-duct measurement for obtaining the desired sound power measurements at a particular point in a duct.

Although many standards exist for the measuring of sound power in ducts, the one most pertinent to this research is ISO 5136-Determination of sound power radiated into a duct by fans and other air-moving devices-In-duct. This standard requires that the duct be oriented in a straight line with minimal transitions to reduce turbulence, and measurements are taken at a specified distance from the source to assure that the air has laminar flow. Turbulence effects are further reduced by using a foam ball, nose cone, or turbulence screen on the end of the microphone. End reflection factors are minimized by having only one inlet and outlet of the duct with an anechoic termination. The specially designed termination limits the ability for a sound wave to reflect back into the duct by eliminating the plane of reflection and flaring the edges of the remaining duct. Finally, the acoustical characteristics are addressed by varying the location of measurements in the duct, limiting the frequency range measured, and using a modal correction factor.

Unfortunately, in-situ measurements of HVAC duct systems do not provide the necessary controlled environment; however, consideration of all three issues can be addressed. The effects of the modal characteristics in the duct can be minimized by varying the location of measurements and averaging data for an equivalent value. The measurement locations will vary within the cross-sectional area of the duct and along the length of a duct. Also, measurements must be taken at a considerable distance from any major disturbance both upstream and downstream. The standard suggests approximately 6 feet or four duct widths to ensure undisturbed flow conditions, and this distance requirement should also be observed for in-situ measurements. The issue of end reflections can also be limited by observing the recommended distances. The influence of the reflected sound would be diminished by the distance to the measurement location.

Finally, the turbulence effects can be further diminished by utilizing one of the microphone protection devices specified by the standard. The foam ball is designed for measurements in air velocities up to $3000 \mathrm{feet} / \mathrm{minute}$ (fpm), and the nose cone is designed for up to $4000 \mathrm{fpm}$. Both of these devices are considered to maintain the omni-directional characteristics of the microphone. The third protective device is referred to as a sampling tube which is a long cylinder that encases the microphone with a slit down the side and a nose cone on the end. The sampling tube is designed for flow velocities of approximately $7800 \mathrm{fpm}$ and is strongly suggested for measurements at or below the $125 \mathrm{~Hz}$ octave band.

\section{Conclusion}

Pursuing a reliable in-situ method of obtaining sound power at a point in an HVAC duct will provide a way of verifying algorithms used to account for the acoustic behavior of individual duct elements. The proposed method is part of a 
larger study to test such algorithms used to predict HVAC acoustics in many software programs. The nature of such a prediction is very complex with many sources of error. By developing a method of measuring sound pressure to obtain sound power, verification of the algorithms can be obtained for any element of the ducted system.

Three main issues must be addressed to obtain reliable sound energy data from a duct. Those three issues - characteristics of acoustical energy, end reflections, and turbulence, affect sound propagation in ducts and any measurements made in the duct. To address these concerns, measurements must be made at a great enough distance from a disturbance upstream or downstream from the duct; they must be made in various locations; and they must be made with appropriate protection from turbulence. Further investigation is required to determine the best approach to accomplish the goal of obtaining sound power at a point in the duct while addressing each issue.

\section{References}

Bies, D. A. and Hansen, C. H. (2003). Engineering Noise Control-Theory and Practice, Spon Press, New York.

International Organization for Standardization. (2003). ISO Standard 5136:2003(E). Acoustics-Determination of sound power radiated into a duct by fans and other air-moving devices-In-duct method, International Organization for Standardization, Switzerland.

Liao, J. (1990). Analysis of Acoustic Energy Propagation in a Circular Duct to Improve the Accuracy of In-duct Noise Measurement. Ph.D. dissertation, Tennessee Technological University.

Ryherd, S. and Wang, L. M. (2005). "Acoustical prediction methods for heating, ventilating, and air-conditioning (HVAC) systems." Proceedings of Noise-Con 2005, Minneapolis, MN, Institute of Noise Control Engineering, Ames, IA. 